\title{
Association of XRCC1 and ERCC2 promoters' methylation with chromatin condensation and sperm DNA fragmentation in idiopathic oligoasthenoteratozoospermic men
}

\author{
Asli Metin Mahmutoglu $^{1}$ | Sezgin Gunes ${ }^{1,2}$ (D) | Ramazan Asci, ${ }^{2,3}$ | Ralf Henkel ${ }^{4,5}$ (i) | \\ Oguz Aydin 6
}

\author{
${ }^{1}$ Faculty of Medicine, Department of \\ Medical Biology, Ondokuz Mayis University, \\ Samsun, Turkey \\ ${ }^{2}$ Department of Multidisciplinary Molecular \\ Medicine, Graduate School of Health \\ Sciences, Ondokuz Mayis University, \\ Samsun, Turkey \\ ${ }^{3}$ Faculty of Medicine, Department of \\ Urology, Ondokuz Mayis University, Samsun, \\ Turkey \\ ${ }^{4}$ Department of Medical Bioscience, \\ University of the Western Cape, Bellville, \\ South Africa \\ ${ }^{5}$ American Center for Reproductive \\ Medicine, Cleveland Clinic, Cleveland, $\mathrm{OH}$, \\ USA \\ ${ }^{6}$ Faculty of Medicine, Department of \\ Pathology, Ondokuz Mayis University, \\ Samsun, Turkey \\ Correspondence \\ Sezgin Gunes, Department of Medical \\ Biology, Faculty of Medicine, Ondokuz \\ Mayis University, 55139, Samsun, Turkey. \\ Email: sgunes@omu.edu.tr \\ Funding information \\ This work was supported by the Commission \\ of Scientific Research Projects of Ondokuz \\ Mayis University (Project no PYO. \\ TIP.1901.18.005).
}

\begin{abstract}
The aim of the study was to investigate whether the promoter methylation of XRCC1 and ERCC2 genes is associated with sperm DNA fragmentation and chromatin condensation in idiopathic oligoasthenoteratozoospermic men. This study involved 77 infertile men with idiopathic oligoasthenoteratozoospermia and 51 normozoospermic controls. The methylight method, TUNEL assay and aniline blue staining were used for the evaluation of XRCC1 and ERCC2 genes' methylation, SDF and sperm chromatin condensation, respectively. SDF ( $p=.004)$ and XRCC1 methylation $(p=.0056)$ were found to be significantly higher in men with idiopathic OAT than in the controls, while mature spermatozoa frequency was higher in controls as compared to infertile men $(p<.0001)$. No significant association was found between SDF and methylation of XRCC1 and ERCC2 genes ( $p=.9277$ and $p=.8257$, respectively). However, compared to the cut-off point obtained by receiver operating characteristic analysis, a significant association was found between SDF and XRCC1 methylation, positive and negative methylation groups, generated according to the cut-off value for XRCC1. $X R C C 1$ methylation was found to have a significant effect on chromatin condensation ( $p=.0017$ ). No significant difference was detected among ERCC2 methylation, male infertility and SDF. In conclusion, XRCC1 methylation may have a role in sperm chromatin condensation and idiopathic OAT.
\end{abstract}

KEYWORDS

chromatin condensation, ERCC2, idiopathic male infertility, sperm DNA fragmentation, XRCC1

\section{1 | INTRODUCTION}

Infertility is defined as a condition where a couple does not achieve a pregnancy after one year of regular, unprotected sexual intercourse and affects $8 \%-12 \%$ of couples worldwide (Inhorn \& Patrizio, 2015; Sharlip et al., 2002). A male factor is the cause of infertility in approximately $50 \%$ of the couples. All the reasons of male factor infertility are not known exactly, and in spite of the progress in the field of male reproductive health, $30 \%-40 \%$ of the infertility cases have still no detectable cause and remain as idiopathic (Agarwal et al., 2019; Bracke et al., 2018). Idiopathic forms of male infertility may result from unknown genetic and/or epigenetic factors (Gunes \& Esteves, 2020; Neto et al., 2016).

Spermatogenesis with a unique epigenetic pattern (Gannon et al., 2014) is exposed to several intrinsic and/or extrinsic factors, culminating in DNA damage in various types of germ cells (Singh et al., 2019b). In germ cells, DNA damage may also result from abnormalities in the protamination process (Muratori \& De 
Geyter, 2018), and DNA repair mechanisms (S. Gunes et al., 2015; Singh et al., 2019b). DNA repair mechanisms are crucial for the protection of germ cell integrity in spermatogenesis and the proper transmission of the genetic information among the generations by eliminating DNA damage (e.g. DNA fragmentation, base and protein adducts) (García-Rodríguez et al., 2019). Recent studies have implicated an association between SDF and methylation of imprinted genes (Ni et al., 2019), infertility (Santi et al., 2018), recurrent pregnancy loss (McQueen et al., 2019), poor embryo development and miscarriage (Borges et al., 2019).

Proliferating germ cells are relatively sensitive to several endoand/or exogenous agents causing various DNA damage during spermatogenesis, at last resulting in infertility in men (Singh et al., 2019b). Abnormalities in the chromatin remodelling process during spermiogenesis (protamination) may also cause DNA fragmentation, which is one of the major types of DNA damage and due to unrepaired nicks of sperm DNA (Aitken \& De luliis, 2010). DNA fragmentation may result from various exogenous factors including cigarette smoking, varicocele, cancer, irradiation and advanced age (Gunes et al., 2018; Kabartan et al., 2019) and has been proposed to be specifically associated with elevated levels of male infertility and pregnancy loss (Zini et al., 2001). Germ cells have various DNA repair mechanisms to protect the genomic integrity and to provide the full transmission of genetic information to the next generations properly (González-Marín et al., 2012; Gunes et al., 2015). Base excision repair (BER) and nucleotide excision repair (NER) systems are two DNA repair mechanisms playing a vital role in the elimination of small DNA lesions and bulky DNA damages in testicular germ cells (González-Marín et al., 2012; Olsen et al., 2001). Single-strand DNA (ssDNA) breaks can indirectly occur as intermediates of the BER pathway, resulting in double-strand DNA (dsDNA) breaks and acceleration of mutation rates if unrepaired (Brem \& Hall, 2005; Caldecott, 2003).

Human X-ray repair cross complementing 1 (XRCC1) and excision repair cross-complementation group 2 (ERCC2) genes take part in the BER and NER pathway, respectively (Krokan \& Bjørås, 2013; Kusakabe et al., 2019). XRCC1 gene codes a scaffold protein with different interacting sub-domains, which assists in the recruitment of BER proteins to the damage site. It also keeps these proteins together at specific locations and therefore accelerates the damage repair (Caldecott, 2019; Nazarkina et al., 2007). The expression of XRCC1 is relatively high in testicular germ cells, especially in spermatocytes and round spermatids (El-Domyati et al., 2010; Walter et al., 1994). However, infertile men have been found to exhibit a lower level of mRNA and protein expression of XRCC1 and a higher level of $\gamma-\mathrm{H} 2 \mathrm{AX}$ than fertile men (Singh et al., 2019b).

ERCC2/XPD gene spanning over 24 exons codes a multifunctional protein which is one of the component of transcription factor II H (TFIH) and plays an important role in the NER pathway via the recognition and verification of the damage (Vashisht \& Wohlschlegel, 2019; Xu et al., 2016). The association between ERCC2 polymorphism(s) and male infertility has been investigated in a limited number of studies (Gu et al., 2007; Ji et al., 2008). A recent study that included association, meta- and trial-sequential analyses has suggested a significant association between the AA variant of ERCC2 751A > C polymorphism and idiopathic infertility risk (Singh et al., 2019a). Downregulation of ERCC2 expression has been indicated in men with testicular azoospermia compared to normal testis (Yang et al., 2004). However, to the best our knowledge, the association of XRCC1 and ERCC2 genes methylation with sperm DNA fragmentation (SDF), chromatin condensation and idiopathic male infertility is not explored yet. Therefore, this present study aimed to investigate the association between promoter methylation of XRCC1 and ERCC2 genes and SDF as well as sperm chromatin condensation in infertile men with idiopathic oligoasthenoteratozoospermia (OAT) and normozoospermic controls.

\section{2 | MATERIALS AND METHODS}

\section{1 | Study participants}

The institutional Review Board of the Ondokuz Mayis University (OMU) approved this study with approval number KAEK 2016/185. All participants signed an informed consent form. Seventy-seven infertile men with idiopathic OAT attending the Urology Clinic, Faculty of Medicine, OMU were enrolled. In addition, a control group consisted of 51 normozoospermic men, of which 32 were fertile. OAT was diagnosed according to WHO criteria (WHO, 2010), when patients displayed the following parameters: density $<15 \times 10^{6}$ spermatozoa $/ \mathrm{ml}$, total motility $<40 \%$ or progressive motility less than $32 \%$, and normal morphology in $<4 \%$ of spermatozoa. Exclusion criteria were karyotype abnormalities, Y-chromosome microdeletions, CFTR mutations, testicular trauma or surgery, infections and any other known causes of male infertility.

\subsection{Semen analysis}

Semen samples from all participants were obtained by masturbation in sterile containers after 2-5 days of sexual abstinence. Following the complete liquefaction of semen samples at $37^{\circ} \mathrm{C}$ for $20-30 \mathrm{~min}$, semen analysis was carried out by using a Microcell counting chamber (Vitrolife) in terms of sperm concentration and motility according to the last edition of World Health Organization (WHO) laboratory manual (WHO, 2010). Semen volume, normal sperm morphology, vitality, $\mathrm{pH}$ and round cell concentration were also evaluated. Following semen analysis, samples were split into three aliquots for methylation analysis (methylight assay), sperm DNA fragmentation (TUNEL assay) and sperm chromatin condensation (aniline blue staining). The methylight assay, TUNEL assay and aniline blue staining could not be performed for all participants due to inadequate semen volume and/or sperm concentration. Prior to methylation analysis, somatic cell lysis procedure, DNA isolation and bisulphite modification process were carried out. 
TAB LE 1 Primers and probes sequences for methylight assay

\begin{tabular}{|c|c|c|c|c|c|c|}
\hline Gene & Nucleotide sequence & $\begin{array}{l}\text { Base } \\
\text { number }\end{array}$ & $\operatorname{Tm}\left({ }^{\circ} \mathrm{C}\right)$ & GC\% & $\begin{array}{l}\text { CpG } \\
\text { number }\end{array}$ & $\begin{array}{l}\text { Amplicon } \\
\text { length (bp) }\end{array}$ \\
\hline$X R C C 1 \mathrm{~F}$ & TTTGTTATCGGCGTAGGATGGTTT & 24 & 59.8 & 41.7 & 2 & \\
\hline XRCC1 Probe & $\begin{array}{l}\text { 6FAM-TACGCTACCCAAACGCTCCAAACCTAAAC- } \\
\text { BHQ-1 }\end{array}$ & 29 & 66.9 & 48.3 & 2 & \\
\hline ERCC2 Probe & $\begin{array}{l}\text { 6FAM-CCTACCCGTCAATCCGCTAAAACAAAAC } \\
\text { CA-BHQ-1 }\end{array}$ & 30 & 67.2 & 46.7 & 2 & \\
\hline АСТВ F & TGGTGATGGAGGAGGTTTAGTAAGT & 25 & - & - & - & \\
\hline ACTB R & AACCAATAAAACCTACTССТСССТTAА & 27 & - & - & - & - \\
\hline
\end{tabular}

Abbreviations: bp, base pair; CpG, cytosine-phosphate-guanine; F, forward; GC, guanine-cytosine; R, reverse; Tm, melting temperature.

\section{3 | Somatic cell lysis}

To obtain pure sperm cells from semen samples, somatic cells were lysed according the procedure described by Mao et al. (2013). First, sperm concentration was adjusted to $<10 \times 10^{6} / \mathrm{ml}$ for each semen sample. Then, seminal plasma was removed by centrifugation at $250 \times \mathrm{g}$ for $8 \mathrm{~min}$ and the pellet was rinsed with 1X PBS. After the washing step, $12 \mathrm{ml}$ somatic cell lysis buffer (SCLB) [0.5\% Triton X-100 and $0.1 \%$ sodium dodecyl sulphate (SDS)] was added and the pellet resuspended for lysis of somatic cells on ice for $25 \mathrm{~min}$. Following the incubation on ice, the sample was centrifuged again and the supernatant containing the somatic cell lysate was removed. The presence of residual somatic cells was controlled microscopically. If the elimination of somatic cells was not complete, the process was repeated until a pure sperm fraction was obtained (Gunes, Agarwal, et al., 2018).

\section{4 | Sperm DNA isolation}

Subsequent to the removal of somatic cells, sperm DNA was isolated using Quick-gDNA Miniprep kit (Zymo Research) according to the manufacturer's recommendations (Gunes, Agarwal, et al., 2018). DNA samples were stored at $-20^{\circ} \mathrm{C}$ up to the next step, bisulphite modification.

\section{5 | Bisulphite modification of sperm DNA and promoter methylation of XRCC1 and ERCC2 genes by methylight method}

Bisulphite modification of isolated sperm DNA was performed by using the EZ DNA Methylation Gold kit (Zymo Research) according to manufacturer's instructions (Gunes, Agarwal, et al., 2018). The methylight method was employed for the assessment of the methylation status of XRCC1 and ERCC2 genes' promoter regions.

\section{6 | Primers and probes design for XRCC1 and ERCC2 genes}

Promoter regions of XRCC1 and ERCC2 genes were determined by using the Gene2Promoter tool, which is the part of Genomatix Software Suite package (Intrexon Bioinformatics). With this tool, it is possible to find a putative promoter region for gene(s) according to the transcription factor binding site. Sequences of XRCC1 and $E R C C 2$ genes retrieved from the National Center for Biotechnology Information (NCBI) gene tool were used in Gene2Promoter software to find the promoter sequences. The program gave more than one promoter sequences for each gene and promoters with experimentally verified 5' complete transcripts were selected. These selected promoter sequences were also compared with the promoter sequences retrieved from the eukaryotic promoter database (EPD) and ENSEMBL for both XRCC1 and ERCC2 genes in the NCBI blast tool in terms of the similarity and cover index. Promoter sequences for the genes with $100 \%$ similarity and the highest cover rate were chosen for primers and probes design. The primers and probes were designed specifically for the fully methylated bisulphite-converted DNA by Beacon Designer 8.2 software (Premier Biosoft, USA) for methylation analysis using the methylight assay. In this study, the probes were designed as oligonucleotides of which the 5 '-ends were linked to a fluorescein reporter (6FAM) and the 3'-ends were linked to a Black Hole Quencher-1 (BHQ1) dye. Primers and probes sequences used in the study are presented in Table 1.

\section{7 | Semi-quantitative real-time PCR method (methylight)}

The methylation status of XRCC1 and ERCC2 promoters was analysed by means of a semi-quantitative real-time PCR method, methylight, using an EpiTect MethyLight PCR + ROX Vial kit (Qiagen) according to the manufacturer's instructions (Eads et al., 2000). In the methylight 
assay, three sets of primers and probes were used, of which two sets were for the XRCC1 and ERCC2 genes and one set for the internal control gene, Actin Beta (ACTB; Eads et al., 2000), which served as a reference to normalise the amount of input DNA (Table 1). EpiTect methylated control DNA (Qiagen, Germany) was also used as a positive control for methylation and to specify the methylation quantity. DNase/RNase free $\mathrm{dH}_{2} \mathrm{O}$ (Invitrogen) was utilised as a negative control in each run. The real-time PCR amplification was performed in a $20 \mu \mathrm{l}$ final reaction volume including $1 \mathrm{X}$ EpiTect methylight master mix, $0.4 \mu \mathrm{M}$ forward primer, $0.4 \mu \mathrm{M}$ reverse primer, $0.2 \mu \mathrm{M}$ probe, 100 ng bisulphite-converted DNA and DNase/RNase free $\mathrm{dH}_{2} \mathrm{O}$ at the following cycling conditions: after the initial PCR activation step at $95^{\circ} \mathrm{C}$ for $5 \mathrm{~min}, 45 \mathrm{cycles}$ at $95^{\circ} \mathrm{C}$ for $15 \mathrm{~s}$ and $60^{\circ} \mathrm{C}$ for $60 \mathrm{~s}$ annealing-extension step in the real-time PCR cycler (Rotorgene Q, Germany). The percent methylated reference (PMR) values for the genes were calculated according to $2^{-\Delta \Delta \mathrm{Ct}}$ method, where $\Delta \Delta \mathrm{C}_{\mathrm{t}}=$ $\left[\left(\mathrm{CT}_{\text {Target }}-\mathrm{CT}_{\text {Reference }}\right)\right.$ sample - $\left(\mathrm{CT}_{\text {Target }}-\mathrm{CT}_{\text {Reference }}\right)$ methylated control DNA] (Livak \& Schmittgen, 2001).

\section{8 | TUNEL analysis}

ssDNA and dsDNA breaks were detected employing the TUNEL assay using fluorescein in situ cell death detection kit (Roche, Penzberg, Germany) according to the manufacturer's instructions. Briefly, the TUNEL assay includes fixation, permeabilisation and labelling processes followed by treating the slides with an anti-fade including 4',6-diamidino-2-phenylindole (DAPI) nuclear staining dye (Temecula, CA, USA).

The spermatozoa were fixed overnight in $3.6 \%$ paraformaldehyde and smeared on poly-L-lysine (Sigma Aldrich) coated slides. The slides were kept in a humid chamber overnight at $4^{\circ} \mathrm{C}$ for the attachment of spermatozoa. Following this process, permeabilisation was performed by using permeabilisation solution $(0.1 \%$ Triton $\mathrm{X}-100$ and $0.1 \%$ tri-sodium citrat-5,5-hydrat in $\mathrm{dH}_{2} \mathrm{O}$ ) for $10 \mathrm{~min}$. In the labelling step, terminal deoxynucleotidyl transferase (TdT) enzyme was utilised for adding fluorescein isothiocyanate-deoxyuridine triphosphate (FITC-dUTP) to 3'-hydroxyl (OH) ss- and dsDNA break sites. In the last step of the TUNEL assay, spermatozoa were counterstained with an anti-fade including DAPI (Kabartan et al., 2019). A negative control without TdT enzyme and a positive control pre-treated with $200 \mathrm{mM} \mathrm{H}_{2} \mathrm{O}_{2}$ for an hour were employed in each run.

Slides were immediately visualised under a fluorescent microscope at 400X magnification (Olympus BX-51). A minimum of three random images including at least 500 spermatozoa from different areas were taken under the microscope for each sample. Samples were blinded to the observer. Spermatozoa showing yellowish FITC-fluorescence were assessed as TUNEL-positive, while those spermatozoa showing bluish DAPI-fluorescence were regarded as TUNEL-negative. The number of TUNEL-positive and TUNELnegative spermatozoa was counted using ImageJ software and the percentage of TUNEL-positive spermatozoa expressed as sperm DNA fragmentation (SDF) index calculated.

\section{9 | Aniline blue staining}

For the evaluation of chromatin condensation, thin smears of the washed semen samples were prepared on a slide and air-dried. Afterwards, slides were fixed for $30 \mathrm{~min}$ in $3 \%$ glutaraldehyde (Merck) in phosphate-buffered saline (PBS) (Thermo Fisher Scientific) and stained with $5 \%$ aniline blue dissolved in $4 \%$ acetic acid (Sigma Aldrich) for $15 \mathrm{~min}$. Slides were then rinsed with tap water (Terquem \& Dadoune, 1983).

Slides were evaluated using a bright field microscope (Olympus CX31) at $1,000 \times$ magnification. Two or three slides were prepared per sample and at least 200 spermatozoa were counted for each sample. Aniline blue staining results in light staining (aniline blue-negative; mature) spermatozoa, intermediate staining all over of the sperm head (aniline blue-intermediate; moderately immature) and strong blue-stained sperm heads (aniline blue-positive; immature) (Óvári et al., 2010). The percentages of immature, mature and moderately immature spermatozoa were calculated for each participant by a ratio between the number of sperm nuclei stained with aniline blue and the total number of counted spermatozoa.

\subsection{0 | Statistical analysis}

Data were statistically analysed using MedCalc Statistical Software version 19.2 (MedCalc Software Ltd). The Shapiro-Wilk test was employed for the determination of normality distribution of the data. Correlation(s) between the data analysed in the study was assessed by the Spearman rank correlation coefficient test, and the MannWhitney test was utilised for variables between different groups. The sensitivity and specificity of SDF and methylation analysis in the distinguishing of infertile men with OAT from control males were evaluated by the receiver operator characteristics (ROC) curve analysis. A probability of $p<.05$ was considered statistically significant.

\section{RESULTS}

A total of 77 infertile men with OAT and 51 normozoospermic controls were included in the study. Table 2 shows the summary statistics as mean $\pm S D$ of the conventional semen parameters, sperm chromatin condensation and SDF of infertile men with OAT and controls. Infertile men with OAT had significantly lower rate of mature spermatozoa (aniline blue-negative spermatozoa) as compared with controls $(p<.0001)$. The rate of mature spermatozoa showed significant $(p<.0001)$ positive correlations with sperm concentration, motility, morphology and age $(p=.0324)$. Moreover, the percentage of mature spermatozoa illustrated a negative correlation with SDF $(p<.0002)$ (Table 3).

SDF analysis was performed by TUNEL assay in 62 infertile men with OAT and 49 normozoospermic men and revealed a significant ( $p=.004)$ difference between OAT patients $(15.4 \% \pm 10.3 \%)$ and the control group $(9.9 \% \pm 8.6 \%)$. SDF showed a positive correlation 
TABLE 2 Semen parameters, SDF and sperm chromatin condensation of infertile men with oat and controls

\begin{tabular}{|c|c|c|c|}
\hline Parameters & OAT $(n=77)$ & $\begin{array}{l}\text { Controls } \\
(n=51)\end{array}$ & $p$-value \\
\hline \multicolumn{4}{|l|}{ Age } \\
\hline Mean $\pm S D$ & $31.9 \pm 5.9$ & $36.1 \pm 5.5$ & $<.0001^{*}$ \\
\hline \multicolumn{4}{|l|}{ Volume (ml) } \\
\hline Mean $\pm S D$ & $3.5 \pm 1.1$ & $3.3 \pm 0.7$ & .323 \\
\hline \multicolumn{4}{|c|}{ Concentration $\left({ }^{*} 10^{6} / \mathrm{ml}\right)$} \\
\hline Mean $\pm S D$ & $4.9 \pm 3$ & $36.1 \pm 13.4$ & $<.0001^{*}$ \\
\hline \multicolumn{4}{|l|}{ Motility (\%) } \\
\hline Mean $\pm S D$ & $15.9 \pm 7.6$ & $49.7 \pm 9.6$ & $<.0001^{*}$ \\
\hline \multicolumn{4}{|c|}{ Morphology (\%) } \\
\hline \multirow[t]{2}{*}{ Mean $\pm S D$} & $2.2 \pm 0.9$ & $7.2 \pm 2.1$ & $<.0001^{*}$ \\
\hline & OAT $(n=72)$ & $\begin{array}{l}\text { Controls } \\
(n=50)\end{array}$ & \\
\hline \multicolumn{4}{|c|}{ Mature spermatozoa (\%) } \\
\hline \multirow[t]{2}{*}{ Mean $\pm S D$} & $70.6 \pm 20.7$ & $89.9 \pm 8.6$ & $<.0001^{*}$ \\
\hline & OAT $(n=62)$ & $\begin{array}{l}\text { Controls } \\
(n=49)\end{array}$ & \\
\hline \multicolumn{4}{|l|}{ SDF } \\
\hline Mean $\pm S D$ & $15.4 \pm 10.3$ & $9.9 \pm 8.6$ & $.004^{*}$ \\
\hline
\end{tabular}

Note: $p<.05$ was considered statistically significant by independent samples $t$ test.

Abbreviations: OAT, oligoasthenoteratozoospermia; $S D$, standard deviation; SDF, sperm DNA fragmentation.

${ }^{*}$ Statistically significant.

with the rate of moderately immature (aniline blue-intermediate) spermatozoa and a negative correlation with sperm concentration $(p=.0002)$, motility $(p=.0004)$ and morphology $(p=.0182)$ (Table 3). Using ROC curve analysis, a cut-off value of $7.92 \%$ for SDF was calculated to distinguish between oligoasthenoteratozoospermic men and controls with a sensitivity and specificity of the SDF test were $77.4 \%$ and $59.2 \%$, respectively, with an area under the ROC curve (AUC) of 0.682 ( $p<.001$; Figure 1).

Methylation analysis of oligoasthenoteratozoospermic men $(n=49)$ and controls $(n=32)$ revealed a significant difference for the levels of methylated DNA (PMR) in the XRCC1 promoter region $[(2.54,95 \% \mathrm{Cl} 1.85-5.12)$ and $(1.63,95 \% \mathrm{Cl} 1.18-2.21)$, respectively, $p=.0056]$. There was a significant negative correlation between XRCC1 methylation and sperm concentration ( $p=.0039)$, morphology $(p=.0125)$ and the percentage of immature spermatozoa ( $p=.0017$; Table 3 ). A cut-off value of $\geq 1.43 \%$ determined by ROC curve analysis using PMR values was obtained with a sensitivity of 83.67\% (95\% Cl: 70.3-92.7) and a specificity of $43.75 \%(95 \% \mathrm{Cl}$ : 26.4-62.3) for XRCC1 gene $(p<.001)$ (Figure 2). The methylation frequency of $X R C C 1$ gene was significantly higher in infertile men than in the controls (Table 4).

There was no difference between the methylation level and frequency of ERCC2 promoter region and male infertility (Table 4). ERCC2 methylation was positively correlated with XRCC1 methylation ( $r=0.246, p=.027)$. We did not obtain a significant cut-off value for ERCC2 methylation in infertile men with OAT and controls ( $A \cup C=0.579, p=.22$ ). In addition, we could not find any significant association between the methylation of XRCC1 and ERCC2 genes and smoking status $(p>.05)$. No significant association was found between SDF and the methylation of both XRCC1 and ERCC2 promoters ( $p=.9277$ and $p=.8257$, respectively). However, compared to cut-off point obtained by ROC analysis, we found a significant association between SDF and XRCC1 methylation groups which were named as positive and negative methylation groups ( $p=.015)$.

\section{4 | DISCUSSION}

In this study, we have investigated the association between the methylation of XRCC1 and ERCC2 genes and SDF in infertile men with OAT and controls. We also investigated the association of chromatin condensation with SDF and the methylation status of these genes. Our results suggest a significant association of the XRCC1 methylation status, chromatin condensation defects and SDF with OAT as compared to controls.

Chromatin condensation abnormalities have been indicated to be associated with male infertility (Hammadeh et al., 2001), poor semen parameters, SDF and epigenetic modifications (Muratori \& De Geyter, 2018). We observed that the rate of mature spermatozoa was statistically lower in infertile men than in the controls. We found that the percentage of immature spermatozoa was negatively correlated with sperm concentration, motility and normal sperm morphology. In addition, the percentage of mature spermatozoa also exhibited a significant negative correlation with SDF, which supports the theory that protamines have a protective role for the DNA (Boissonnas et al., 2013; Yu et al., 2014). Infertile men have higher levels of SDF than fertile men (Zini et al., 2001), which was confirmed in our study. Moreover, SDF showed a negative correlation with spermatogenesis, motility, sperm concentration as well as normal sperm morphology. These results are also consistent with the literature (Homa et al., 2019; Le et al., 2019; H. Yang et al., 2019).

To distinguish between OAT and normozoospermic subjects, a cut-off value of $>7.92 \%$ with a sensitivity of $77.4 \%$ and a specificity of $59.2 \%$ (AUC: $0.682, p<.001$ ) was calculated for SDF. This cut-off value is clearly lower than the cut-off values that are calculated to distinguish between fertile and infertile men to predict fertilisation success in assisted reproduction (Bungum et al., 2008; Hassanen et al., 2019; Ribas-Maynou et al., 2013; Sharma et al., 2010) and may result from the inclusion of not only normozoospermic men but also fertile men in the control group. In addition, the relatively small sample size might have contributed to this low cut-off value. Although SDF may originate from various causes including abortive apoptosis, abnormalities in chromatin remodelling and aberrations in DNA repair mechanisms, the exact cause(s) is/are not yet known (Gonzalez-Marin et al., 2012). SDF could be accumulated as an intermediate form during several DNA repair pathways, for example BER pathway; if the pathways do not work properly (Brem \& Hall, 2005; 


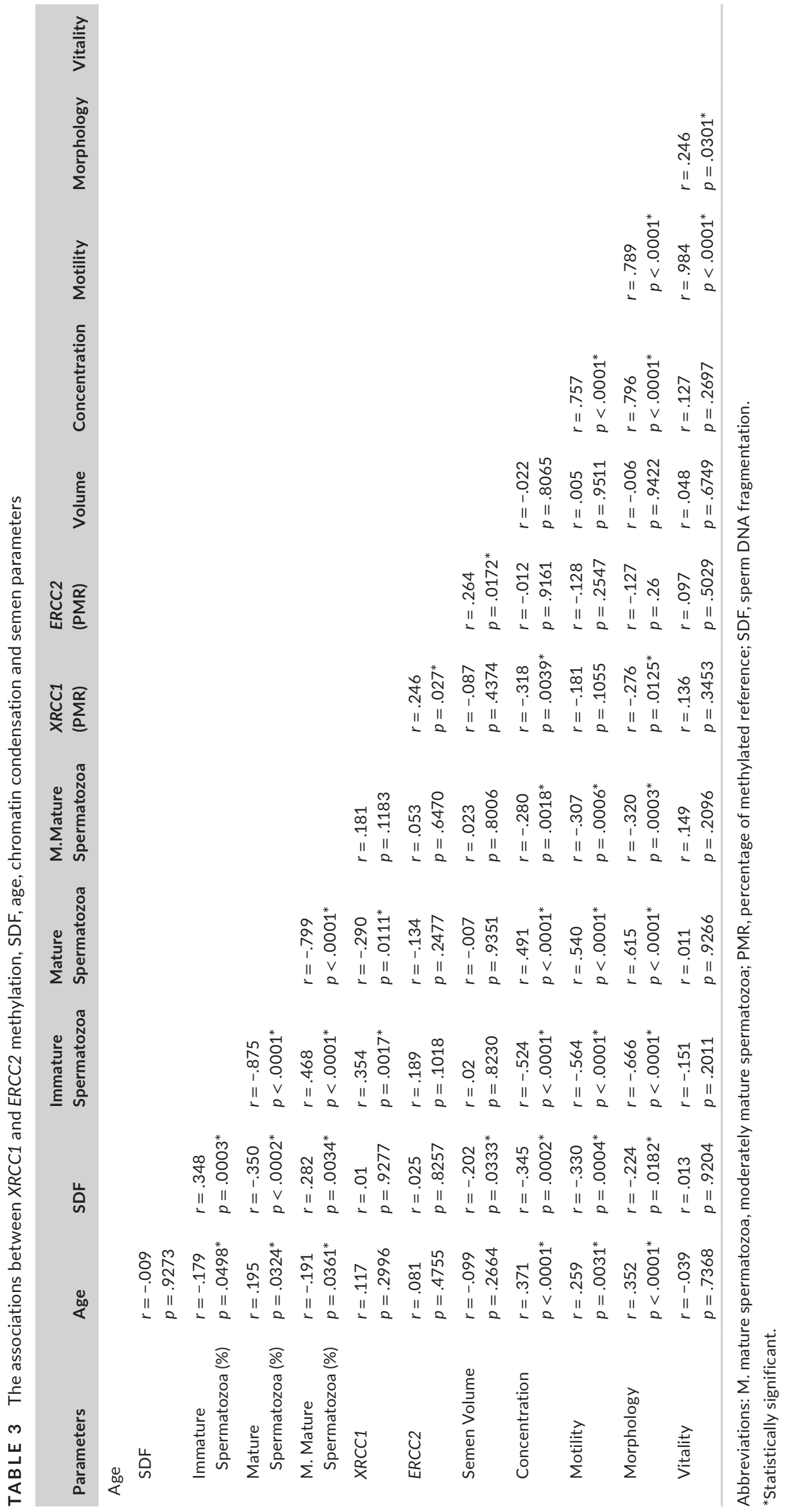




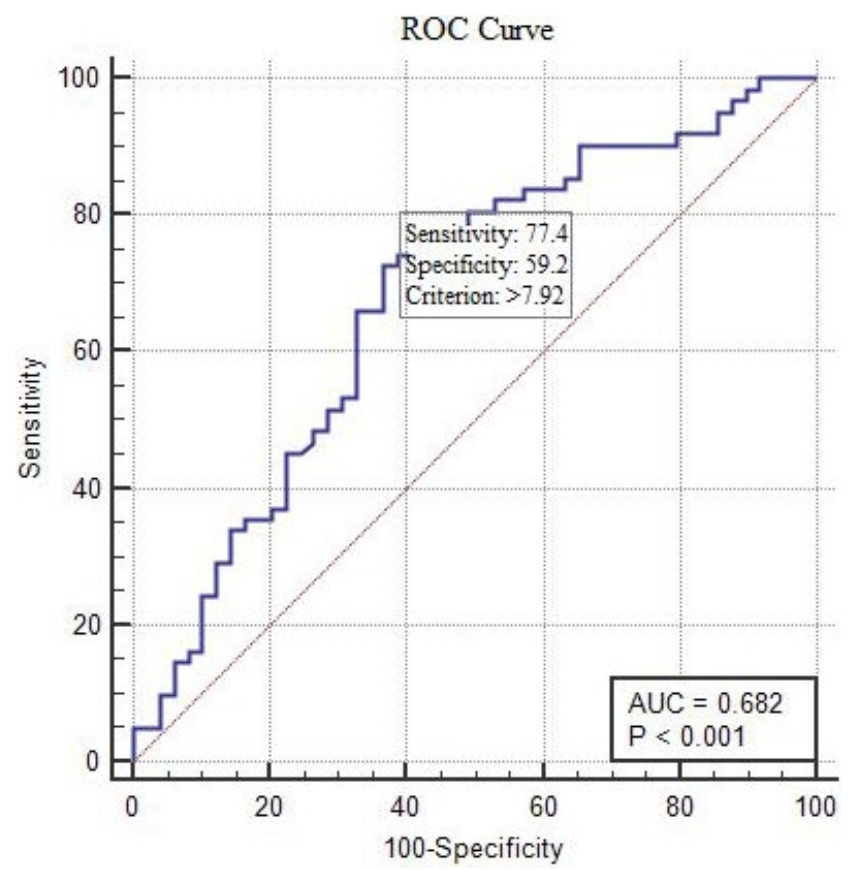

FIGURE 1 Sensitivity and specificity of the ROC curve analysis for SDF. AUC, area under the ROC curve

Caldecott, 2003), thus one has to assume that this process of sperm DNA damage is multi-factorial.

XRCC1 plays a role in the BER pathway by its association with the recruitment of proteins involved in the pathway and accelerating the repair of lesion(s) via acting as a scaffold protein (Caldecott, 2019;

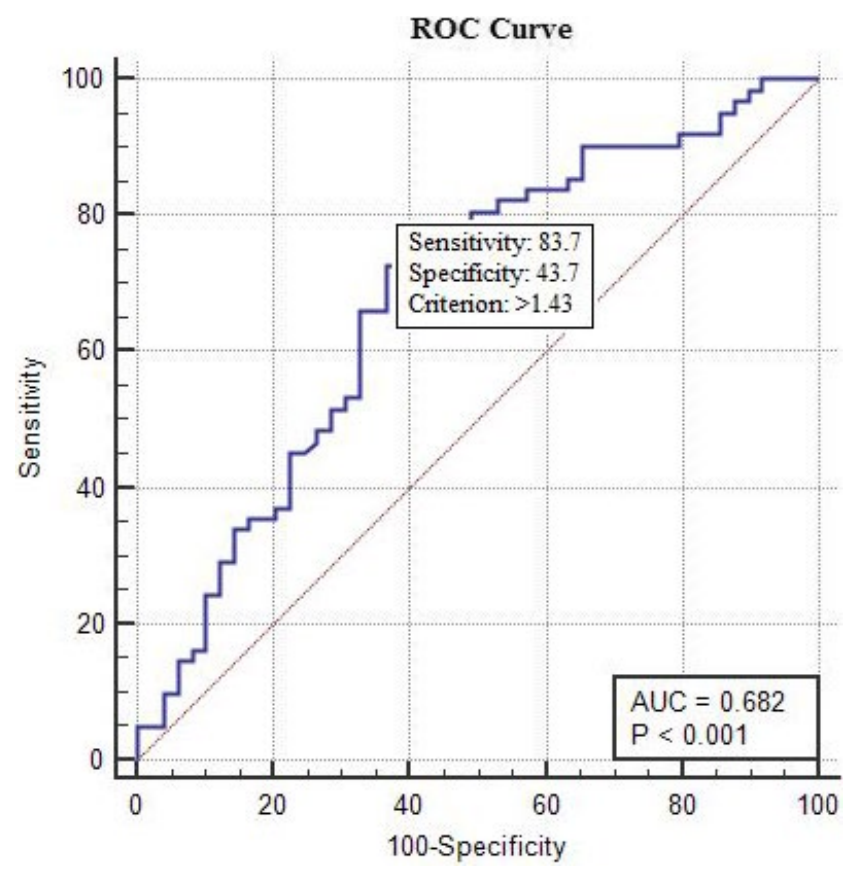

FIGURE 2 Sensitivity and specificity of the ROC curve analysis for DNA methylation status of XRCC1. AUC, area under the ROC curve
Nazarkina et al., 2007). Xrcc1 has been shown to be essential for embryonic development in mice and $\mathrm{Xrcc}^{-/-}$embryos with high level of DNA fragmentation without any exposure were highly susceptible to DNA-damaging agents (Tebbs et al., 1999). Methylation of a gene's regulatory region, as well as gene knock-out, may cause the alteration(s) of the gene transcription (Gannon et al., 2014). We could not find any significant association between the methylation of XRCC1 and SDF in our study population ( $p=.93)$. Xrcc1 was also suggested to be pivotal for spermatogenesis and Xrcc1 deficiency in primordial germ cells from mice gave rise to impaired spermatogenesis culminating male infertility (C. Xu et al., 2019) and our result that $X R C C 1$ methylation is negatively associated with sperm concentration and normal morphology is in accordance with that. Moreover, $X R C C 1$ has been proposed to have a function in the chromatin remodelling process during spermatid elongation (Zheng et al., 2012). This is corresponding to our observation of a significant positive correlation between defective chromatin condensation and XRCC1 promoter methylation. Reportedly, XRCC1 expression is high in human testicular germ cells, especially spermatocytes and round spermatids (El-Domyati et al., 2010; Singh et al., 2019b).

Young fertile men have been suggested to have a significantly higher levels of XRCC1 in their testis than infertile men with varicocele and old men (El-Domyati et al., 2010). XRCC1 mRNA and protein expression was reported also to be higher in men with oligozoospermia and oligoasthenozoospermia than in normozoospermic and fertile men (Singh et al., 2019b). XRCC1 promoter methylation may be one of the causes of alterations in the expression of XRCC1 transcript and protein level. In our study, we observed a significant increase in the percentage and frequency of XRCC1 methylation in infertile men with OAT as compared to the normozoospermic controls. Similarly, DNA mismatch repair gene MLH1 promoter methylation was found to be significantly associated with oligozoospermia (Gunes, Agarwal, et al., 2018); whereas no significant association could be found between homologous recombinational repair genes $B R C A 1$ and BRCA2 promoter methylation and male factor infertility (Kabartan et al., 2019).

ERCC2, which is the main component of TFIIH, recognises and verifies the DNA damage in NER pathway (Vashisht \& Wohlschlegel, 2019). ERCC2 polymorphism (A > C, rs13181, p.Lys751GIn) has been found to be associated with idiopathic male infertility in some studies (Gu et al., 2007; Singh et al., 2019a), while other studies have not found this association (Ji et al., 2008). The XPD 751GIn allele has been implicated to be a risk factor for idiopathic azoospermia (Gu et al., 2007; Singh et al., 2019a). We did not find a significant association between ERCC2 promoter methylation and idiopathic male infertility $(p=.2271)$. We found a significant positive correlation of ERCC2 methylation with XRCC1 methylation, which may result from the involvement of XRCC1 to NER pathway as well as BER pathway. According to ROC curve analysis, ERCC2 methylation is not a prognostic factor for male infertility, specifically for OAT. On the other hand, the smoking status has not been found to be associated with the promoter methylation of ERCC2 ( $p>.05)$. 


\begin{tabular}{|lllll} 
Gene & Methylation & Infertile $(\boldsymbol{n}=49)$ & Control $(\boldsymbol{n}=32)$ & $p$-value \\
\hline \multirow{2}{*}{ XRCC1 } & Methylation frequency (\%) & $41(83.7)$ & $19(59.4)$ & $.015^{*}$ \\
& PMR [Median (Q1-Q3)] & $2.54(1.61-7.8)$ & $1.63(0.71-3.34)$ & $.0056^{*}$ \\
\multirow{2}{*}{ ERCC2 } & Methylation frequency (\%) & $21(42.9)$ & $8(25)$ & .101 \\
& PMR [Median (Q1-Q3)] & $0.05(0.02-0.08)$ & $0.03(0.01-0.06)$ & .2271 \\
\hline
\end{tabular}

TABLE 4 Methylation frequency and PMR value of XRCC1 and ERCC2 genes in infertile men and controls

Note: $p<.05$ was considered statistically significant.

Methylation frequency was calculated by the number of individuals with methylated genes divided by the total number of individuals by chi-square test. PMR was used to measure the percentage of fully methylated molecules at a specific locus, and the median and interquartile range was evaluated by Mann-Whitney test.

Abbreviation: PMR, percentage of methylated reference.

${ }^{*}$ Statistically significant.

It is important to emphasise that this study has some limitations including the relatively small sample size and semi-quantitative nature of the detection of the methylation status. Additionally, our study involved only two genes playing important roles in the BER and NER pathways; however, these pathways include numerous genes. Investigating more genes involved in these pathways may be more informative about the role and importance of these genes in DNA damage and/or male infertility.

In conclusion, our results show that the methylation pattern of $X R C C 1$ may have a role in the quality of spermatozoa, chromatin condensation and idiopathic OAT. To find out the possible role of ERCC2 promoter methylation in DNA fragmentation and/or male infertility, large sample cohorts and the investigation of other promoters belonging to 14 transcripts of ERCC2 with a total of 15 transcript variants are required to reveal the possible role of the promoter methylation of ERCC2. Further studies investigating more genes involved in BER and NER pathways and all putative promoters belonging to the studied genes are warranted to understand the molecular mechanisms of idiopathic OAT and SDF.

\section{ACKNOWLEDGEMENTS}

We thank the Commission of Scientific Research Projects of Ondokuz Mayis University for the financial support of this study.

\section{DATA AVAILABILITY STATEMENT}

The data that support the finding of this study are available from the corresponding author [SG], upon reasonable request.

\section{ORCID}

Sezgin Gunes iD https://orcid.org/0000-0002-3103-6482

Ralf Henkel iD https://orcid.org/0000-0003-1128-2982

\section{REFERENCES}

Agarwal, A., Panner Selvam, M. K., Samanta, L., Vij, S. C., Parekh, N., Sabanegh, E., Tadros, N. N., Arafa, M., \& Sharma, R. (2019). Effect of Antioxidant Supplementation on the Sperm Proteome of Idiopathic Infertile Men. Antioxidants, 8(10), 488. https://doi.org/10.3390/antio x8100488

Aitken, R. J., \& De luliis, G. N. (2010). On the possible origins of DNA damage in human spermatozoa. Molecular Human Reproduction, 16(1), 3-13. https://doi.org/10.1093/molehr/gap059
Boissonnas, C. C., Jouannet, P., \& Jammes, H. (2013). Epigenetic disorders and male subfertility. Fertility and Sterility, 99(3), 624-631. https://doi.org/10.1016/j.fertnstert.2013.01.124

Borges, E., Zanetti, B. F., Setti, A. S., Braga, D. P. D. A. F., Provenza, R. R., \& laconelli, A. (2019). Sperm DNA fragmentation is correlated with poor embryo development, lower implantation rate, and higher miscarriage rate in reproductive cycles of non-male factor infertility. Fertility and Sterility, 112(3), 483-490. https://doi.org/10.1016/j. fertnstert.2019.04.029

Bracke, A., Peeters, K., Punjabi, U., Hoogewijs, D., \& Dewilde, S. (2018). A search for molecular mechanisms underlying male idiopathic infertility. Reproductive BioMedicine Online, 36(3), 327-339. https://doi. org/10.1016/j.rbmo.2017.12.005

Brem, R., \& Hall, J. (2005). XRCC1 is required for DNA single-strand break repair in human cells. Nucleic Acids Research, 33(8), 2512-2520. https://doi.org/10.1093/nar/gki543

Bungum, M., Spano, M., Humaidan, P., Eleuteri, P., Rescia, M., \& Giwercman, A. (2008). Sperm chromatin structure assay parameters measured after density gradient centrifugation are not predictive for the outcome of ART. Human Reproduction, 23(1), 4-10. https://doi. org/10.1093/humrep/dem353

Caldecott, K. W. (2003). XRCC1 and DNA strand break repair. DNA Repair, 2(9), 955-969. https://doi.org/10.1016/S1568-7864(03)00118-6

Caldecott, K. W. (2019). XRCC1 protein; Form and function. DNA Repair, 81, 102664. https://doi.org/10.1016/j.dnarep.2019.102664

Eads, C. A., Danenberg, K. D., Kawakami, K., Saltz, L. B., Blake, C., Shibata, D., \& Laird, P. W. (2000). MethyLight: A high-throughput assay to measure DNA methylation. Nucleic Acids Research, 28(8), e32. https://doi.org/10.1093/nar/28.8.e32

El-Domyati, M. M., Al-Din, A.-B.-M., Barakat, M. T., El-Fakahany, H. M., Honig, S., Xu, J., \& Sakkas, D. (2010). The expression and distribution of deoxyribonucleic acid repair and apoptosis markers in testicular germ cells of infertile varicocele patients resembles that of old fertile men. Fertility and Sterility, 93(3), 795-801. https://doi.org/10.1016/j. fertnstert.2008.10.031

Gannon, J. R., Emery, B. R., Jenkins, T. G., \& Carrell, D. T. (2014). The sperm epigenome: Implications for the embryo. Elisabetta Baldi \& Monica Muratori In Genetic Damage in Human Spermatozoa (pp. 5366). Springer.

García-Rodríguez, A., Gosálvez, J., Agarwal, A., Roy, R., \& Johnston, S. (2019). DNA Damage and repair in human reproductive cells. International Journal of Molecular Sciences, 20(1), 31. https://doi. org/10.3390/ijms20010031

Gonzalez-Marin, C., Gosalvez, J., \& Roy, R. (2012). Types, causes, detection and repair of DNA fragmentation in animal and human sperm cells. International Journal of Molecular Sciences, 13(11), 1402614052. https://doi.org/10.3390/ijms131114026

González-Marín, C., Gosálvez, J., \& Roy, R. (2012). Types, causes, detection and repair of DNA fragmentation in animal and human sperm 
cells. International Journal of Molecular Sciences, 13(11), 1402614052. https://doi.org/10.3390/ijms131114026

Gu, A., Ji, G., Liang, J., Xia, Y., Lu, N., Wu, B., \& Wang, X. (2007). DNA repair gene XRCC1 and XPD polymorphisms and the risk of idiopathic azoospermia in a Chinese population. International Journal of Molecular Medicine, 20(5), 743-747.

Gunes, S., Agarwal, A., Henkel, R., Mahmutoglu, A., Sharma, R., Esteves, S., \& Pelegrini, L. (2018). Association between promoter methylation of MLH 1 and MSH 2 and reactive oxygen species in oligozoospermic men-A pilot study. Andrologia, 50(3), e12903.

Gunes, S., Al-Sadaan, M., \& Agarwal, A. (2015). Spermatogenesis, DNA damage and DNA repair mechanisms in male infertility. Reproductive BioMedicine Online, 31(3), 309-319. https://doi.org/10.1016/j. rbmo.2015.06.010

Gunes, S., \& Esteves, S. C. (2020). Role of genetics and epigenetics in male infertility. Andrologia, e13586. https://doi.org/10.1111/and.13586

Gunes, S., Metin Mahmutoglu, A., Arslan, M. A., \& Henkel, R. (2018). Smoking-induced genetic and epigenetic alterations in infertile men. Andrologia, 50(9), e13124. https://doi.org/10.1111/and.13124

Hammadeh, M., Zeginiadov, T., Rosenbaum, P., Georg, T., Schmidt, W., \& Strehler, E. (2001). Predictive value of sperm chromatin condensation (aniline blue staining) in the assessment of male fertility. Archives of Andrology, 46(2), 99-104. https://doi.org/10.1080/01485010117363

Hassanen, E., Elqusi, K., Zaki, H., Henkel, R., \& Agarwal, A. (2019). TUNEL assay: Establishing a sperm DNA fragmentation cut-off value for Egyptian infertile men. Andrologia, 51(10), e13375. https://doi. org/10.1111/and.13375

Homa, S., Vassiliou, A., Stone, J., Killeen, A., Dawkins, A., Xie, J., Gould, F., $\&$ Ramsay, J. (2019). A comparison between two assays for measuring seminal oxidative stress and their relationship with sperm DNA fragmentation and semen parameters. Genes (Basel), 10(3), 236. https:// doi.org/10.3390/genes10030236

Inhorn, M. C., \& Patrizio, P. (2015). Infertility around the globe: New thinking on gender, reproductive technologies and global movements in the 21st century. Human Reproduction Update, 21(4), 411426. https://doi.org/10.1093/humupd/dmv016

Ji, G., Gu, A., Xia, Y., Lu, C., Liang, J., Wang, S., Ma, J., Peng, Y., \& Wang, X. (2008). ERCC1 and ERCC2 polymorphisms and risk of idiopathic azoospermia in a Chinese population. Reproductive BioMedicine Online, 17(1), 36-41. https://doi.org/10.1016/S1472 -6483(10)60290-8

Kabartan, E., Gunes, S., Arslan, M. A., \& Asci, R. (2019). Investigating the relationship between BRCA1 and BRCA2 genes methylation profile and sperm DNA fragmentation in infertile men. Andrologia, 51, e13308.

Krokan, H. E., \& Bjørås, M. (2013). Base excision repair. Cold Spring Harbor Perspectives in Biology, 5(4), a012583. https://doi.org/10.1101/cshpe rspect.a012583

Kusakabe, M., Onishi, Y., Tada, H., Kurihara, F., Kusao, K., Furukawa, M., Iwai, S., Yokoi, M., Sakai, W., \& Sugasawa, K. (2019). Mechanism and regulation of DNA damage recognition in nucleotide excision repair. Genes Environ, 41, 2. https://doi.org/10.1186/s41021-019-0119-6

Le, M. T., Nguyen, T. A. T., Nguyen, H. T. T., Nguyen, T. T. T., Nguyen, V. T., Le, D. D., Nguyen, V. Q. H., \& Cao, N. T. (2019). Does sperm DNA fragmentation correlate with semen parameters? Reproductive Medicine and Biology, 18(4), 390-396. https://doi.org/10.1002/rmb2.12297

Livak, K. J., \& Schmittgen, T. D. (2001). Analysis of relative gene expression data using real-time quantitative PCR and the $2-\triangle \Delta C T$ method. Methods, 25(4), 402-408. https://doi.org/10.1006/meth.2001.1262

Mao, S., Goodrich, R. J., Hauser, R., Schrader, S. M., Chen, Z., \& Krawetz, S. A. (2013). Evaluation of the effectiveness of semen storage and sperm purification methods for spermatozoa transcript profiling. Systems Biology in Reproductive Medicine, 59(5), 287-295. https://doi. org/10.3109/19396368.2013.817626
McQueen, D. B., Zhang, J., \& Robins, J. C. (2019). Sperm DNA fragmentation and recurrent pregnancy loss: A systematic review and meta-analysis. Fertility and Sterility, 112(1), 54-60. https://doi. org/10.1016/j.fertnstert.2019.03.003

Muratori, M., \& De Geyter, C. (2018). Chromatin condensation, fragmentation of DNA and differences in the epigenetic signature of infertile men. Best Practice \& Research Clinical Endocrinology \& Metabolism, 33(1), 117-126.

Nazarkina, Z. K., Khodyreva, S. N., Marsin, S., Lavrik, O. I., \& Radicella, J. P. (2007). XRCC1 interactions with base excision repair DNA intermediates. DNA Repair (Amst), 6(2), 254-264. https://doi.org/10.1016/j. dnarep.2006.10.002

Neto, F. T. L., Bach, P. V., Najari, B. B., Li, P. S., \& Goldstein, M. (2016). Genetics of male infertility. Current Urology Reports, 17(10), 70. https://doi.org/10.1007/s11934-016-0627-x

Ni, W., Pan, C., Pan, Q., Fei, Q., Huang, X., \& Zhang, C. (2019). Methylation levels of IGF2 and KCNQ1 in spermatozoa from infertile men are associated with sperm DNA damage. Andrologia, 51(5), e13239.

Olsen, A. K., Bjortuft, H., Wiger, R., Holme, J., Seeberg, E., Bjoras, M., \& Brunborg, G. (2001). Highly efficient base excision repair (BER) in human and rat male germ cells. Nucleic Acids Research, 29(8), 17811790. https://doi.org/10.1093/nar/29.8.1781

Óvári, L., Sati, L., Stronk, J., Borsos, A., Ward, D. C., \& Huszar, G. (2010). Double probing individual human spermatozoa: Aniline blue staining for persistent histones and fluorescence in situ hybridization for aneuploidies. Fertility and Sterility, 93(7), 2255-2261. https://doi. org/10.1016/j.fertnstert.2009.05.033

Ribas-Maynou, J., García-Peiró, A., Fernández-Encinas, A., Abad, C., Amengual, M. J., Prada, E., Navarro, J., \& Benet, J. (2013). Comprehensive analysis of sperm DNA fragmentation by five different assays: TUNEL assay, SCSA, SCD test and alkaline and neutral Comet assay. Andrology, 1(5), 715-722. https://doi. org/10.1111/j.2047-2927.2013.00111.x

Santi, D., Spaggiari, G., \& Simoni, M. (2018). Sperm DNA fragmentation index as a promising predictive tool for male infertility diagnosis and treatment management - meta-analyses. Reproductive BioMedicine Online, 37(3), 315-326. https://doi.org/10.1016/j. rbmo.2018.06.023

Sharlip, I. D., Jarow, J. P., Belker, A. M., Lipshultz, L. I., Sigman, M., Thomas, A. J., Schlegel, P. N., Howards, S. S., Nehra, A., Damewood, M. D., Overstreet, J. W., \& Sadovsky, R. (2002). Best practice policies for male infertility. Fertility and Sterility, 77(5), 873-882. https://doi. org/10.1016/S0015-0282(02)03105-9

Sharma, R. K., Sabanegh, E., Mahfouz, R., Gupta, S., Thiyagarajan, A., \& Agarwal, A. (2010). TUNEL as a test for sperm DNA damage in the evaluation of male infertility. Urology, 76(6), 1380-1386. https://doi. org/10.1016/j.urology.2010.04.036

Singh, V., Bansal, S. K., Sudhakar, D. V. S., Neelabh Chakraborty, A., Trivedi, S., Gupta, G., Thangaraj, K., Rajender, S., \& Singh, K. (2019a). SNPs in ERCC1, ERCC2, and XRCC1 genes of the DNA repair pathway and risk of male infertility in the Asian populations: Association study, meta-analysis, and trial sequential analysis. Journal of Assisted Reproduction and Genetics, 36(1), 79-90. https://doi.org/10.1007/ s10815-018-1339-6

Singh, V., Mohanty, S. K., Verma, P., Chakraborty, A., Trivedi, S., Rajender, S., \& Singh, K. (2019b). XRCC1 deficiency correlates with increased DNA damage and male infertility. Mutation Research/Genetic Toxicology and Environmental Mutagenesis, 839, 1-8. https://doi. org/10.1016/j.mrgentox.2019.01.004

Tebbs, R. S., Flannery, M. L., Meneses, J. J., Hartmann, A., Tucker, J. D., Thompson, L. H., Cleaver, J. E., \& Pedersen, R. A. (1999). Requirement for the Xrcc1DNA base excision repair gene during early mouse development. Developmental Biology, 208(2), 513-529. https://doi. org/10.1006/dbio.1999.9232 
Terquem, A., \& Dadoune, J. (1983). Aniline blue staining of human spermatozoon chromatin. Evaluation of nuclear maturation. Jean Andre In The sperm cell (pp. 249-252). Springer.

Vashisht, A. A., \& Wohlschlegel, J. A. (2019). Role of Human Xeroderma Pigmentosum Group D (XPD) Helicase in various cellular pathways. Renu Tuteja Helicases from All Domains of Life (pp. 125-139). Elsevier.

Walter, C. A., Lu, J., Bhakta, M., Zhou, Z. Q., Thompson, L. H., \& McCarrey, J. R. (1994). Testis and somatic Xrcc-1 DNA repair gene expression. Somatic Cell and Molecular Genetics, 20(6), 451-461. https://doi. org/10.1007/BF02255837

WHO (2010). WHO laboratory manual for the examination and processing of human semen 2010. WHO.

Xu, C., Xu, J., Ji, G., Liu, Q., Shao, W., Chen, Y., Gu, J., Weng, Z., Zhang, X., Wang, Y., \& Gu, A. (2019). Deficiency of X-ray repair cross-complementing group 1 in primordial germ cells contributes to male infertility. The FASEB Journal, 33(6), 7427-7436. https://doi.org/10.1096/ fj.201801962RR

Xu, H., Feng, Y., Jia, Z., Yang, J., Lu, X., Li, J., \& Chen, J. (2016). Association between ERCC1 rs3212986 and ERCC2 rs13181 gene polymorphisms in NER pathway and the risk of bladder cancer in a Chinese population. International Journal of Clinical and Experimental Pathology, 9(2), 2295-2300.

Yang, B., Chen, B., Wang, H., Gao, X., Zhang, Y.-Q., Liu, H.-L., \& Shao, C. (2004). Expression and significance of Rap1A in testes of azoospermic subjects. Asian Journal of Andrology, 6(1), 35-40.

Yang, H., Li, G., Jin, H., Guo, Y., \& Sun, Y. (2019). The effect of sperm DNA fragmentation index on assisted reproductive technology outcomes and its relationship with semen parameters and lifestyle. Translational
Andrology and Urology, 8(4), 356-365. https://doi.org/10.21037/ tau.2019.06.22

Yu, B., Qi, Y., Liu, D., Gao, X., Chen, H., Bai, C., \& Huang, Z. (2014). Cigarette smoking is associated with abnormal histone-to-protamine transition in human sperm. Fertility and Sterility, 101(1), 51-57. e51. https://doi.org/10.1016/j.fertnstert.2013.09.001

Zheng, L. R., Wang, X. F., Zhou, D. X., Zhang, J., Huo, Y. W., \& Tian, H. (2012). Association between XRCC1 single-nucleotide polymorphisms and infertility with idiopathic azoospermia in northern Chinese Han males. Reproductive BioMedicine Online, 25(4), 402-407. https://doi.org/10.1016/j.rbmo.2012.06.014

Zini, A., Bielecki, R., Phang, D., \& Zenzes, M. T. (2001). Correlations between two markers of sperm DNA integrity, DNA denaturation and DNA fragmentation, in fertile and infertile men. Fertility and Sterility, 75(4), 674-677. https://doi.org/10.1016/s0015-0282(00)01796-9

How to cite this article: Metin Mahmutoglu A, Gunes S, Asci

$\mathrm{R}$, Henkel R, Aydin O. Association of XRCC1 and ERCC2 promoters' methylation with chromatin condensation and sperm DNA fragmentation in idiopathic oligoasthenoteratozoospermic men. Andrologia. 2021;53:e13925. https://doi.org/10.1111/and.13925 